\title{
Perceptions of the Police: The Role of Need for Cognition and Numeracy
}

\author{
Carolyn Pham ${ }^{(D)}$, Jiuqing Cheng \\ Department of Psychology, University of Northern lowa, United States
}

\begin{abstract}
The public's perceptions of the police are related to people's willingness to obey the law and cooperate with law enforcement. Past research has found that demographics affect perceptions of the police. This study hypothesizes that those with a higher level of need for cognition and numeracy have more positive attitudes toward the police, possibly because they are more likely to recognize the importance and necessity of the police. 443 U.S. residents participated in this study via MTurk in May 2019. The demographic variables of age, gender, education, race, income, political ideology and party affiliation were collected. Crime rate was estimated via zip code obtained by searching IP address. Participants also completed the need for cognition, subjective and objective sales. As a result, in addition to replicating the role of demographic variables and crime rate, the study found that after controlling for demographics and crime rate, perceptions of the police were positively related to need for cognition and subjective and objective numeracy. Overall, this study indicates that thinking disposition and cognitive ability play a significant role in how the public perceives the police. The study also implies that perceptions of the police was a class issue. Future studies on hot social issues could extend their focus to cognitive factors.
\end{abstract}

Key words: need for cognition, numeracy, perceptions of the police, thinking disposition

\section{Introduction}

The Importance of Studying Perceptions of the Police

Studying public perceptions of the police is critical. Police forces represent and enforce the law, and their legitimacy is largely asso- ciated with the public's evaluation of their work (Garcia \& Cao, 2005; Taylor \& Lawton, 2012). Positive perceptions of the police are beneficial to society because they can promote peace and cooperation with the police (Cao \& Wu, 2019; Cao, Zhao, Ren, \& Zhao, 2015; Manning, 2010; Stack, Cao, \& Adamzyck, 2007; Wu, Lake, \& Cao, 2015). For example, previous research has found that at least

Correspondence concerning this article should be addressed to Jiuqing Cheng, Bartlett 2068, Department of Psychology, University of Northern lowa, Cedar Falls, lowa, United States, 50614.

E-mail: jiuqing.cheng@uni.edu

Received December 26, 2019 
some degree of positive interaction is necessary for law enforcement to complete their duties both effectively and efficiently (Brandl \& Horvath, 1991). Positive interactions with the public can lead to higher levels of trust and confidence in the police. This in turn is linked with higher rates of cooperation with the police and compliance with the law (Myhill \& Bradford, 2012). Additionally, some studies have stated that measuring the public's opinions toward the police should serve as a way to measure police effectiveness (Brown \& Benedict, 2002; Cao, 2011; Ren, Cao, Lovrich, \& Gaffney, 2005). Thus, by conducting research on perceptions of the police, a greater understanding about people's willingness to obey the law, cooperate with cops, and judgments of police legitimacy can be achieved (Sunshine \& Tyler, 2003). Following this rationale, the present study aims to further investigate the demographic and psychological factors that affect people's perceptions of the police.

The Role of Demographic Variables in Perceptions of the Police

Research on perceptions of the police so far has largely focused on the role of demographic variables. For example, while people in general hold a positive view of the police (Cao \& Wu, 2019), there are differences when views are broken down by race. The general trend shows that White Americans' views are the most positive followed by Hispanics' and Black Americans' views respectively (Cao \& Wu, 2019; Ekins, 2016; Lai \& Zhao, 2010; Pew Research Center, 2017; Wu, 2014). Persons who identify as a racial minority or nonWhite have a tendency to hold more negative views and attitudes toward the police when compared to White Americans in a meta-review by Peck (2015). This review also found that Hispanic participants have a more pos- itive view of the police than Black participants. While the majority of studies on racial differences in attitude toward the police focus on comparisons among White, Black, and Hispanic views, only a few include Asian perspectives as well (e.g., Wu, 2014). It is worth noting that in the United States, Asians have the 4th highest population (5.8\%) in the 2010 Census. Hence, to test perceptions of the police more comprehensively, the present study includes four racial groups: White, Black, Hispanic, and Asian.

Views of the police are also often associated with party affiliation and political ideology. For example, studies suggest that Republicans are more likely than Democrats to view the police positively and have confidence in them (Brown, 2017; Fingerhut, 2017). Additionally, people with a more conservative ideology view the police more favorably as opposed to those with a more liberal ideology (Ekins, 2016).

In addition to the demographic variables mentioned above, a national survey conducted by the Cato Institute with a sample size of one thousand respondents found that perceptions of the police were positively related to age, education, and income (Ekins, 2016). The results were consistent with findings from other studies with regards to age (Dai \& Jiang, 2016; Reisig \& Parks, 2000), education (Frank, Smith, \& Novak, 2005; Jang, Joo, \& Zhao, 2010; Weitzer \& Tuch, 2005), and income (Barboza 2012; Frank et al., 2005).

\section{The Possible Effect of Psychological Factors on Perceptions of the Police}

Thus far, a series of studies have demonstrated that perceptions of the police are affected by a variety of demographic variables as reviewed above. The present study contends that in addition to demographic variables, psychological factors also play a significant 
role in how the public perceives the police. Specifically, this study focuses on the relationship between the way that people think and process information (i.e., need for cognition, subjective and objective numeracy) and their attitudes toward the police. We present our rationale below.

Psychological research has long found that people's judgments are affected by how they think. One of the most well-known examples of this is the availability heuristics. This heuristics is evidenced when people overestimate the probability of an event that easily comes to mind as opposed to what is statistically true (Tversky \& Kahneman, 1974). Familiarity of an event can affect how easy it is to recall; this, in turn, can cause people to overlook the statistical reality and rely on easily accessible incidents. For example, people will often incorrectly believe that death by homicide occurs more frequently than death by stomach cancer (Slovic, Fischhoff, Lichtenstein, \& Roe, 1981).

In a series of studies, Tversky and Kahneman postulated that simple heuristics can lead to biased judgments and decisions such as baserate neglect, the framing effect, conjunction fallacy, and so forth (e.g., Kahneman, 2003; Tversky \& Kahneman, 1974; 1981; 2002). On the other hand, past research has discovered that people who rely more on deliberative thinking rather than simple heuristics have fewer biases. For example, it was found that greater cognitive reflection was associated with less base-rate neglect and conjunction fallacy (Frederick, 2005; Thomson \& Oppenheimer, 2016). In medical decisions, when participants were asked to engage in deliberation by analyzing both advantages and disadvantages of different treatment options, they were more likely to recognize the nature of the treatment and hence, the framing effect was reduced (Almashat, Ayotte, Edelstein, \& Margrett, 2008).
Following the research stated above, the present study examines the role of need for cognition and numeracy in how people evaluate and perceive the police. These two factors were chosen because they pertain to the way people think about and their ability to utilize information. Need for cognition (NFC) refers to the tendency that people have to enjoy effortful thinking (Cacioppo \& Petty, 1982; Cacioppo, Petty, Feinstein, \& Jarvais, 1996). That is, whereas individuals with a lower NFC are more likely to use other means of judgment to make sense of the world, such as heuristics, people with a higher NFC, in general, are more likely to have positive attitudes toward situations that require more reasoning and problem-solving, and they are likely to respond more substantively to situations that require deeper processing as well (Cacioppo et al., 1996; Verplanken, Hazenberg, \& Palenwen, 1992).

The trait of NFC is associated with thinking dispositions. For instance, those who have a higher NFC are more likely to engage in information-seeking behaviors and evaluate the quality of information more thoroughly than those with a lower NFC (Cacioppo et al., 1996; Petty, Briñol, Loersch, \& McCaslin, 2009). Juric (2017) found that higher NFC students read more professional and scientific books than students with a lower NFC. Meanwhile, compared to lower NFC students, higher NFC students indicated that they were more willing to read long and complicated books. West, Toplak, and Stanovich (2008) concluded that NFC was positively associated with critical thinking. That is, after controlling for general cognitive ability, higher NFC individuals were still better able to perform logical reasoning even when logic conflicted with their prior beliefs.

Thus, based on the evidence above, we predict that NFC is positively related to perceptions of the police. Admittedly, people's 
attitude toward the police can be affected by their own uncomfortable experiences or news reports about police brutality. However, the police are necessary and crucial to public safety; research has found the police contribute significantly to crime- and victimization cost reduction (Gramlich, 2019). Moreover, a significant number of cities in the United States lack a sufficient police force (Chalfin \& McCrary, 2013; 2018). We believe that people with a higher NFC are more likely to recognize the necessity and value of the police and that their contributions outweigh their limitations. Thus, we hypothesize that higher NFC individuals have more positive perceptions of the police as opposed to lower NFC individuals.

The second psychological factor of interest is numeracy. There are two types of numeracy: subjective numeracy and objective numeracy. While the former refers to the tendency, motivation, and confidence in using numerical information, the latter represents the cognitive ability to comprehend and utilize numerical information (Fagerlin et al., 2007; Peters \& Bjalkebring, 2015; Sinayev \& Peters, 2015). Numeracy, particularly objective numeracy, has received much attention in research, and it has been linked to biased judgment and decision making. For example, in past research, lower numerate people made more impulsive selections in intertemporal choices (Cheng, 2020; Sinayev \& Peters, 2015) and showed a greater deviation from the axiom of expected value in gambling choices (Jasper, Bhattacharya, \& Corser, 2017). In medical decisions, lower numerate people relied more on simple heuristics (e.g., affect heuristics) rather than objective numerical information (e.g., probability of treatment effect, Reyna, Nelson, Han, \& Dieckmann, 2009).

We believe that numeracy correlates with perceptions of the police for two reasons. First, when assessing police effectiveness, people process numerical information such as crime rate, clearance rate, victimization rate, the number of sworn officers, and the cost of the department. The willingness and ability to comprehend such information may affect how people evaluate the police. Second, beyond dealing with numerical information, numeracy has been found to tap into thinking dispositions due to its relationship with non-numerical judgment and cognitive tasks. For example, in a study by Thomson and Oppenheimer (2016), numeracy was found to be positively associated with performance on logical reasoning (syllogism) even when the conclusions contradicted with priori beliefs. Patel (2017) demonstrated that numeracy positively correlated with open-minded thinking and the belief in evolution and negatively correlated with conspiracy beliefs. Moreover, numeracy was positively associated with NFC and negatively associated with the tendency to apply simple heuristics. Therefore, similar to our prediction with regard to NFC, we believe that higher numerate people can better capture the function and contribution of the police and hence have more positive attitudes toward the police.

\section{Goals of the Current Study}

The present study has two major goals. First, this study aims to replicate past findings regarding the relationship between demographic variables and perceptions of the police. Given the reproducibility crisis in research on psychology (American Psychological Association, 2015), we believe replications are needed to further elucidate the role of demographics in attitude toward police. Second and more importantly, this study examines the role of need for cognition and numeracy in perceptions of the police, particularly after controlling for the demographic variables. The aim of this study is to show whether thinking disposition and cognitive ability can 
explain the unique variability in how people perceive the police. Regarding numeracy, the majority of studies so far have focused on objective numeracy. The present study tests both subjective and objective numeracy and predicts that their impact on perceptions of the police is similar.

Like past studies (for a review, see Peck, 2015), the present study collects data from U.S. residents. Such an approach might limit the study's external validity. However, need for cognition and numeracy are two basic cognitive traits in humans across nations. Moreover, some past studies also showed similarities in perceptions of the police between different countries (e.g., Dai \& Jiang, 2016; Jang et al., 2010). Thus, we believe the findings from the current study still have the potential to be generalized. More details about this issue are discussed in the Limitations section.

\section{Methods}

\section{Participants}

This study received IRB approval before data collection. Participants were recruited using Amazon TurkPrime and were limited to people living in the United States over the age of 18, who self-identified as Asian, Black or African American, Hispanic or Latinx, or White or Caucasian American. Data collection was performed in May 2019. There were 440 participants who were recruited for this study. Five participants who self-identified as more than one race were excluded from the current study, and two participants who stated that they did not tell the truth were removed as well. ${ }^{1}$ As a result, there were 433 participants

\footnotetext{
${ }^{1}$ At the end of the survey, participants were asked whether they told the truth when answering previous items. Participants were informed that they would receive payment regardless of their answer for this question.
}

remaining: 126 (29.1\%) White, 86 (19.9\%) Hispanic, 114 (26.3\%) Black, and 107 (24.7\%) Asian. The racial distribution in the present study did not reflect the racial distribution in the United States; however, because we were aiming to examine and replicate the racial differences in perceptions of the police, the sample size should be balanced across the four racial groups (Maxwell, Kelley, \& Rausch, 2008). Such an approach was also employed in other studies testing the relationship between race and attitudes toward the police (Schuck, Rosenbaum, \& Hawkins, 2008; Weitzer \& Tuch, 2005). Participants received $\$ 1.50$ for compensation.

A sensitivity analysis was performed with G*Power 3.1.9 to estimate the effect size that could be detected with the current sample size; $\alpha$ was set at .05 , and statistical power was set at .80 . As a result, the study had sufficient power to detect a coefficient of determination $\left(R^{2}\right)$ as low as .05 in a multiple regression with all demographic variables and psychological factors (for details please refer to the Results section). Hence, the sample size should be sufficient to capture meaningful patterns in perceptions of the police.

\section{Materials \& Procedures}

Participants were provided an online consent form and only continued with the survey if they agreed with it. The following eight questionnaires were completed:

Perceptions of the Police Scale. The Perceptions of the Police Scale (Nadal \& Davidoff, 2015) contains 12 items and uses a 5-point Likert type scale where one end denotes "strongly disagree" and the other denotes "strongly agree." Example statements from the scale include, "I like the police" and "The police do not discriminate." The scale is meant to measure general perceptions of the police, beliefs about police bias, and beliefs about 
discriminatory behavior by the police (Nadal \& Davidoff, 2015). An average was taken across the items to represent the perceptions of the police. A higher score indicates more positive perceptions of the police.

Subjective Numeracy Scale. The subjective numeracy scale (Fagerlin et al., 2007) asks participants to rate on a 6-point Likert scale how comfortable they are working with numbers. Participants are asked questions including "How good are you at working with fractions?" and "How good are you at calculating a 15\% tip?" There are 8 items on this scale. This scale features questions that were developed to predict participants' abilities to complete numerically-intensive tasks while still being quick and acceptable for surveys conducted over the internet or over the phone (Fagerlin et al., 2007). An average was taken across the items to indicate the level of subjective numeracy. A higher score indicates higher subjective numeracy.

Objective Numeracy Scale. The objective numeracy scale (Weller et al., 2013) contains eight entry-type-items that were developed to measure participants' abilities to comprehend and handle numerical information (e.g., making conversions between percentages, proportions, and probabilities). Example question: Imagine that we roll a fair, six-sided die 1,000 times. Out of 1,000 times, how many times do you think the die will come up as an even number? Answers for each item were graded as either correct or incorrect. The number of correctly answered items (out of eight) was computed for each participant. A higher score from this scale reflects better objective numeracy.

Need for Cognition. The need for cognition scale (Cacioppo \& Petty, 1982; Cacioppo, Petty, $\&$ Kao, 2013) uses a 5-point Likert scale where 1 denotes "extremely uncharacteristic of me" and 5 denotes "extremely characteristic of me." The scale contains 18 items. Example statements on this scale include "I find satisfaction in deliberat- ing hard and for long hours" and "I only think as hard as I have to." An average was taken across the items to indicate the level of need for cognition in a person. A higher score indicates a higher tendency to employ deeper thinking (Cacioppo \& Petty, 1982).

Demographic variables. After completing the scales presented above, participants were asked to report their demographic information including race, age, gender, education, annual household income, social and fiscal ideology, and political party affiliation. Education was coded with six levels: $1=$ Less than high school graduate, 2 = High school graduate or equivalent, 3 = Some college or Associate's degree, 4 = Bachelor's degree, 5 = Master's degree, 6 = Doctoral degree. Annual household income was measured with 12 levels and ranged between under $\$ 9,999$ and above $\$ 100,000$ with increments of $\$ 10,000$. Social ideology and fiscal ideology were measured separately, each of which used a 7-point Likert scale where 1 = extremely liberal and 7 = extremely conservative. Party affiliation provided four options: 1 = Democrat, 2 = Independent, 3 = Republican, and 4 = Other.

Crime rate estimate. The current study did not ask participants to report their location or perceived neighborhood safety. To estimate crime rate, we first used participants' IP address to locate their zip code via IP location finder (https://tools.keycdn.com/geo). Then, based on the zip code, we used AreaVibes (https://www.areavibes.com/), a popular website to find city and neighborhood information in the United States, to obtain corresponding crime rate (per 100,000 people) We were mindful that such an approach was relatively novel and indirect, and hence might not be perfectly accurate. Thus, to test this approach's validity, as shown below, correlations were made between crime rate and other variables to examine whether some past findings could be replicated. 
Table 1 Means and standard deviations of the demographic variables and crime rate

\begin{tabular}{cccccc}
\hline Age & Education & Income & $\begin{array}{c}\text { Social } \\
\text { Ideology }\end{array}$ & $\begin{array}{c}\text { Fiscal } \\
\text { Ideology }\end{array}$ & $\begin{array}{c}\text { Crime rate/per } \\
100,000 \text { people }\end{array}$ \\
\hline 38.60 & 3.15 & 5.41 & 3.79 & 3.88 & 3304.5 \\
$(16.07)$ & $(1.08)$ & $(3.44)$ & $(1.70)$ & $(1.72)$ & $(1661.9)$ \\
\hline
\end{tabular}

Note. Numbers in parentheses are standard deviations.

\section{Results}

SPSS 24.0 was employed to perform the analyses of descriptive statistics, correlations and regressions, as shown below and in the appendix.

\section{Demographic Variables}

Across 433 participants, there were 278 (64.2\%) females and 155 (35.8\%) males. As for party affiliation, there were 201 (46.4\%) Democrats, 127 (29.3\%) Independents, 83 (18.9\%) Republicans, and 18 (4.2\%) Others. There were four participants who did not disclose their party affiliation. Such a finding was consistent with another study that discovered that there were more Democrats than Republicans among MTurk workers (Levay, Freese, \& Druckman, 2016).

Table 1 presents the means and standard deviations of the other demographic variables and crime rate collected in the present study. On average, the sample had an education level between some college or Associate's degree and Bachelor's degree. The average income level was between $\$ 40,000$ and $\$ 59,999$. The mean ideology was close to centrist (slightly liberal) in both social and fiscal domains. There was a very high positive correlation in ideology between the two domains, $r(427)=.79, p<.001$. To reduce redundancy, a combined ideology composite was generated by averaging the values between the two scales. This combined composite was employed in the following analyses. As for crime rate, across all participants, we did not find a zip code in eleven cases. In four additional cases we could not obtain a crime rate from the zip code. Thus, the analyses of crime rate were based on 418 participants. ${ }^{2}$

Performance on Scales of Perceptions of the Police, Need for Cognition, and Subjective and Objective Numeracy

Table 2 exhibits the means, standard deviations, minimum and maximum values, and reliabilities of the perceptions of the police scale, need for cognition scale, and subjective and objective numeracy scales, respectively. All scales had good or acceptable reliability. For the dependent variable of the present study (perceptions of the police), the mean was greater than the midpoint of the scale (2.5). Across all participants, $81.2 \%$ of responders had a score greater than 2.5. Thus, on average, participants had more favorable views of the police in the present study. This pattern was consistent with previous research (Cao \& Wu, 2019).

\section{Correlations between Perceptions of the Police and Other Variables}

Table 3 presents the zero-order correlations between perceptions of the police and other

\footnotetext{
${ }^{2}$ The median of crime rate was 3225.5 , which was very close to the mean. Additionally, applying natural-log transformation to crime rate increased its skewness from a slightly moderate level (.63) to a severe level (1.1). Therefore, in the analyses below, we adopted the original values for crime rate.
} 
variables. Consistent with past research (Barboza, 2012; Brown, 2017; Dai \& Jiang, 2016; Jang et al., 2010), it was found that perceptions of the police were significantly positively related to age, education, income, and conservative ideology. More specifically, according to Cohen (1988) where .1, .3, and .5 were used to describe a weak, medium and strong relationship, respectively, the relationship between age and perception of the police close to a medium or moderate level. The relationships between perceptions of the police and education, income and political ideology were between the weak and medium level.

Additionally, there was a significantly negative relationship between estimated crime rate and perceptions of the police. Crime rate was also significantly negatively associated with income. While the magnitude of these relationships was not so strong, our results of crime rate were still consistent with past findings (Choe, 2008; Jesilow, Meyer, \& Namazzi, 1995; Sampson \& Bartusch, 1998) and thus should be valid to some extent.

In line with other studies, the psychological factors of need for cognition, subjective numeracy, and objective numeracy were positively related to one another (Liberali, Reyna, Furlan, Stein, \& Pardo, 2012; Patel, 2017). Hence, their validity was further checked. The present study also replicated the gender effect in both subjective and objective numer-

Table 2 Performance on the scales of perceptions of police, need for cognition, and subjective and objective numeracy

\begin{tabular}{lcccc}
\hline & Mean (SD) & $\begin{array}{c}\text { Minimum } \\
\text { value }\end{array}$ & $\begin{array}{c}\text { Maximum } \\
\text { value }\end{array}$ & $\begin{array}{c}\text { Cronbach's } \\
\alpha\end{array}$ \\
\hline Perceptions of the police & $3.34(0.94)$ & 1 & 5 & .96 \\
Need for cognition & $3.12(0.60)$ & 1.28 & 5 & .83 \\
Subjective numeracy & $3.90(1.12)$ & 1 & 6 & .85 \\
Objective numeracy & $3.25(2.01)$ & 0 & 8 & .73 \\
\hline
\end{tabular}

Table 3 Zero-order correlations between perception of police and other variables

\begin{tabular}{lcccccccccc}
\hline & DV & Age & Gender & Edu & Income & Ideology & NFC & SN & ON & CR \\
\hline DV & -- & $.28^{* * *}$ & .002 & $.17^{* * *}$ & $.19^{* * *}$ & $.22^{* * *}$ & $.16^{* * *}$ & $.24^{* * *}$ & $.25^{* * *}$ & $-.14^{* *}$ \\
Age & & -- & .09 & $.20^{* * *}$ & .08 & $.16^{* *}$ & .02 & .06 & .08 & -.05 \\
Gender & & & -- & $.12^{*}$ & $.14^{* *}$ & -.07 & .004 & $.18^{* * *}$ & $.16^{* *}$ & .05 \\
Edu & & & & -- & $.40^{* * *}$ & $-.10^{*}$ & $.10^{*}$ & $.29^{* * *}$ & $.24^{* *}$ & -.01 \\
Income & & & & & -- & -.02 & .06 & $.17^{* * *}$ & $.21^{* * *}$ & $-.18^{* *}$ \\
Ideology & & & & & -- & -.05 & -.03 & -.09 & -.06 \\
NFC & & & & & & & -- & $.30^{* * *}$ & $.15^{* *}$ & -.01 \\
SN & & & & & & & & -- & $.42^{* * *}$ & .06 \\
ON & & & & & & & & & -- & -.08
\end{tabular}

Note. DV: dependent variable, perceptions of the police, Edu: education, Ideology: combined composite, NFC: need for cognition, SN: subjective numeracy, ON: objective numeracy, CR: Crime rate

$* \mathrm{p}<.05 ; * * \mathrm{p}<.01 ; * * * \mathrm{p}<.001$. 
acy (Peters \& Bjalkebring, 2015; Thomson \& Oppenheimer, 2016). Additionally, education was positively associated with all three psychological factors. Both subjective and objective numeracy also had positive correlations with income.

Consistent with our predictions, perceptions of the police were positively related to all three psychological factors, which indicated that those who preferred to consider information more comprehensively and deliberatively, preferred to rely on numerical information, and/or had better capacity to comprehend and utilize numerical information had more positive views of the police. As for magnitude, it is worth noting that the relationships between numeracy and perceptions of the police were approaching the medium level, whereas the relationship between need for cognition and perceptions of the police was relatively weak.

To test the relationship between race and perceptions of the police, a one-way ANOVA was performed. The main effect of race was significant, $F(3,429)=12.53, p<.001$. Post-hoc $t$-tests revealed that Black participants (mean $=$ $2.90, S D=0.87$ ) had significantly more negative views of the police when compared to White ( mean $=3.55, S D=0.99)$, Hispanic (mean $=3.38$, $S D=0.92$ ) or Asian participants (mean $=3.52$, $S D=0.83)$, all $p$-values $<.001$. There were no significant differences in perceptions of the police among White, Hispanic, and Asian participants, all $p$-values $>.168$. Thus, the present study replicated past findings that Black participants had more negative views of the police (Cao \& Wu, 2019; Peck, 2015; Wu, 2014).

To test the relationship between party affiliation and perceptions of the police, a one-way ANOVA was conducted. ${ }^{3}$ The main effect of party affiliation was significant, $F(2,408)=19.96$, $p<.001$. Post-hoc $t$-tests indicated that Repub-

3 Those who reported other were excluded from this analysis because only 18 participants did so. licans (mean $=3.89, S D=0.85)$ had more positive views of the police than Democrats (mean = $3.17, S D=0.84$ ) and Independents (mean $=3.31$, $S D=0.96)$, respectively, both $p$-values $<.001$. There was no significant difference between Democrats and Independents, $p=.180$.

The results showed some initial support for our hypotheses. That is, the psychological factors of need for cognition and subjective and objective numeracy were all positively associated with perceptions of the police. However, we were mindful of some limitations with zero-order correlations. First, the probability of Type I error might be inflated due to multiple simultaneous correlations. Second, it was not clear whether psychological factors could still predict perceptions of the police in the presence of the demographic variables and crime rate.

The Effects of Need for Cognition and Subjective and Objective Numeracy on Perceptions of the Police in the Presence of Demographic Variables

To address the issues above, a hierarchical linear regression was performed with perceptions of the police as the dependent variable. In the first block, age, gender, race, education, income, ideology, party affiliation and crime rate were entered. In the second block, need for cognition, subjective numeracy, and objective numeracy were entered. Our rationale was to test the function of need for cognition and numeracy in the presence of demographics and crime rate. In such a way we could test the unique role of psychological factors. In the regression, race was dummy-coded with Black participants as the reference level. This was done because the ANOVA showed that Black participants had significantly more negative views of the police, whereas there were no significant differences in perceptions of the police among the other racial groups. 
Party affiliation was also dummy-coded with Republicans as the reference level. Table 4 shows the results.

As displayed in Table 4, in the first block, age, race, ideology, and party affiliation were significantly related to perceptions of the police in the presence of all demographic variables and crime rate. More importantly, as depicted in the second block, after controlling for demographic variables and crime rate, need for cognition and subjective numeracy were still positively related to perceptions of the police. Objective numeracy's relationship with perceptions of the police was at a marginal significance level $(p=.071)$ when taking other variables into account.

Table 4 Regression: effects of need for cognition and subjective and objective numeracy in the presence of the demographic variables and crime rate

\begin{tabular}{|c|c|c|c|c|c|c|}
\hline Blocks and Variables & $\mathrm{B}(\mathrm{SE})$ & Beta & $R^{2}$ & $\begin{array}{c}R^{2} \\
\text { change }\end{array}$ & $\begin{array}{c}F \\
\text { change }\end{array}$ & Tolerance \\
\hline Block 1 & & & .22 & .22 & $9.61^{* * *}$ & \\
\hline Age & $.01(.003)^{* * *}$ & $.20^{* * *}$ & & & & .78 \\
\hline Gender & $-.09(.09)$ & -.05 & & & & .95 \\
\hline Whites vs. Blacks & $.34(.12)^{* *}$ & $.17^{* *}$ & & & & .53 \\
\hline Hispanics vs. Blacks & $.38(.13)^{* *}$ & $.16^{* *}$ & & & & .67 \\
\hline Asians vs. Blacks & $.50(.11)^{* *}$ & $.24^{* *}$ & & & & .58 \\
\hline Education & $.07(.05)$ & .08 & & & & .73 \\
\hline Income & $.02(.01)$ & .08 & & & & .75 \\
\hline Ideology & $.09(.03)^{* *}$ & $.16^{* *}$ & & & & .79 \\
\hline Democrats vs. Republicans & $-.27(.13)^{*}$ & $-.15^{*}$ & & & & .40 \\
\hline Independents vs. Republicans & $-.30(.13)^{*}$ & $-.15^{*}$ & & & & .50 \\
\hline Crime rate & $\begin{array}{l}-2.9 * 10^{-5} \\
\left(2.6 * 10^{-5}\right)\end{array}$ & -.05 & & & & .91 \\
\hline Block 2 & & & .28 & .06 & $9.96^{* * *}$ & \\
\hline Age & $.01(.003)^{* * *}$ & $.20^{* * *}$ & & & & .77 \\
\hline Gender & $-.15(.09)$ & -.08 & & & & .92 \\
\hline Whites vs. Blacks & $.32(.12)^{* *}$ & $.16^{* *}$ & & & & .52 \\
\hline Hispanics vs. Blacks & $.39(.13)^{* *}$ & $.17^{* *}$ & & & & .66 \\
\hline Asians vs. Blacks & $.42(.13)^{* *}$ & $.20^{* *}$ & & & & .53 \\
\hline Education & $.03(.05)$ & .03 & & & & .70 \\
\hline Income & $.02(.01)$ & .06 & & & & .74 \\
\hline Ideology & $.09(.03)^{* *}$ & $.17^{* *}$ & & & & .77 \\
\hline Democrats vs. Republicans & $-.22(.13)$ & $-.12^{\mathrm{a}}$ & & & & .40 \\
\hline Independents vs. Republicans & $-.24(.13)$ & $-.12^{\mathrm{a}}$ & & & & .49 \\
\hline \multirow[t]{2}{*}{ Crime rate } & $-3.9 * 10^{-5}$ & -.07 & & & & .90 \\
\hline & $\left(2.6 * 10^{-5}\right)$ & & & & & \\
\hline Need for Cognition & $.16(.07)^{*}$ & $.11^{*}$ & & & & .92 \\
\hline Subjective Numeracy & $.13(.04)^{* *}$ & $.15^{* *}$ & & & & .72 \\
\hline Objective Numeracy & $.04(.02)^{\mathrm{a}}$ & $.09^{a}$ & & & & .72 \\
\hline
\end{tabular}

Note. Gender: female is the reference level, Race: Blacks is the reference level, Ideology: a larger value indicates more conservative, Party affiliation: Republicans is the reference level. ${ }^{*} p<.05 ;{ }^{* *} p<.01 ;{ }^{* * *} p<.001 ; \mathrm{a}: p<.10$. 
It is worth mentioning two issues here. First, one might wonder whether to test objective numeracy and subjective numeracy in separate regressions because they were highly correlated with each other. As shown in the appendix, when being tested separately, each type of numeracy was significant in the presence of demographic variables, crime rate and need for cognition. Such a pattern was consistent with the notion that numeracy correlated with perception of the police. Second, as our crime rate variable was indirect, we tested a regression without this variable. As exhibited in the appendix, when excluding the variable of crime rate from the regression analysis, there was little change in results and conclusion.

Taken together, the study found that perceptions of the police were correlated to not only demographic variables but also to people's thinking style and ability to comprehend and utilize information. Our hypotheses received support. The findings and implications, as well as potential limitations, are discussed below.

\section{Discussion}

The present study examined the role of demographic and psychological factors in perceptions of the police. As stated, there is a positive relationship between how the public perceives the police and whether the public chooses to cooperate and obey the law (Myhill \& Bradford, 2012; Sunshine \& Tyler, 2003). In addition, positive interactions between the police and the public can promote law enforcement's efficiency (Brandl \& Horvath, 1991). Thus, understanding the factors underlying perceptions of the police is pivotal. Our results could give researchers insight as to what factors may contribute to negative or positive perceptions of the police.

In line with recent research (Cao \& Wu, 2019), participants in the present study, in general, held relatively positive views of the police. Moreover, the findings regarding the role of demographic variables in perceptions of the police were generally consistent with previous studies. For example, similar to other studies (Cao \& Wu, 2019; Peck, 2015), this study found that Black participants had more negative views of the police than did other racial groups. Past research has found that Americans, especially Black Americans, in low-income areas face a disproportionate amount of police brutality and overall negative interactions with law enforcement (Arafat-Payne, Hitchens, \& Chambers, 2018; Weitzer \& Tuch, 2002), which would unsurprisingly result in these groups having more negative perceptions of the police. Whereas Asian participants were not usually included in past studies, the current study found that Asian participants' attitudes toward the police were at a comparable level with that of White and Hispanic participants' attitudes. Additionally, this study replicated the findings that perceptions of the police were associated with party affiliation and political ideology (Brown, 2017; Fingerhut, 2017). Specifically, the current work found that Republicans had more positive views of the police than Democrats or Independents. This study also revealed that a more conservative ideology was associated with more positive attitudes toward the police. Based on zero-order correlations, perceptions of the police were related to education, age, and income. Similar to other studies (Jesilow et al., 1995; Sampson \& Bartusch 1998), the present work also discovered a negative relationship between perceptions of the police and crime rate. Together, the present study replicated the findings that demographics, socioeconomic status and crime rate had a significant role in how people view the police.

The present study went beyond demographic variables as well. This study contend- 
ed that perceptions of the police should also be associated with psychological factors. Consistently, this study found that, based on zero-order correlations, the need for cognition and subjective and objective numeracy were all positively related to perceptions of the police. Most importantly, with multiple regression, this study demonstrated that after controlling for a series of demographic variables, the psychological factors were still associated with perceptions of the police. Such results implied that how people comprehend, think, and utilize information could explain additional unique variability in perceptions of the police. Specifically, this study indicated that those who had a stronger preference and better abilities to engage in deep thinking instead of applying simple heuristics had more positive attitudes toward the police. Thus, the study added to the literature about the relationship between thinking disposition and social judgement.

The study generated some implications. First, as shown in the correlation matrix, there were significant inter-correlations between education, income, need for cognition and numeracy. Usually, if one has a higher degree and more sophisticated thinking style, then they likely had the income and resources needed to attain higher education in the first place. Thus, our findings also implicated a class issue and echoed the relationships between socioeconomic status, poverty and police violence (Motley \& Joe, 2018). Second and related to the point above, our findings could implicate not only what factors may be relevant in studying people's perceptions of the police, but it would assist in research the other way around as well; future researchers could use these findings to further study what demographics the police may hold biases against. For example, if the police are more biased against a certain racial or age group, such a group is also likely to have a more neg- ative perception of the police. Third, the study also implied that for controversial and hot social issues, in addition to demographics and socioeconomic status, the role of cognitive factors can be examined. For instance, recent studies investigated the function of cognitive tendencies and biases in 2016 United States' Presidential Elections and United Kingdom's 2016 Referendum on European Union Membership (Pennycook \& Rand, 2019; Sumner, Scofield, Buchanan, Evans, \& Shearing, 2018).

\section{Limitations}

While the present study provided evidence to support the role of need for cognition and numeracy in the public's views on the police, several limitations should be acknowledged and discussed.

Personal contact and media effect. As reviewed, past research on perceptions of the police mainly focused on demographics. The present study tested the role of need for cognition and numeracy in the presence of a series of demographic variables and crime rate. We aimed to bring cognitive factors to the field and provide some initial evidence. Thus, our hypotheses and approach were relatively novel. However, we recognized our variables were not exhaustive. For example, some past studies found that personal contact or personal experience with the police was significantly associated with the attitude toward the police (e.g., Dai \& Jiang, 2016; Myhill \& Bradford, 2012; Ren et al., 2005). Thus, the present study was limited without testing personal contact. However, as noted in Barboza (2011) and Weitzer and Tuch (2002), a significant proportion of people never or seldom interacted with police officers. Furthermore, several published studies on perceptions of the police did not include personal contact but still yielded meaningful results (Drakulich \& Crutchfield, 2013; McCluskey, McCluskey, \& 
Enriquez, 2008; MacDonald \& Stokes, 2006; Peck, 2005; Sunshine \& Tyler, 2003;). For instance, a comparative study about people's attitude toward the police with over 15,000 cases across fifteen countries identified significant predictors (e.g., age, political ideology, life satisfaction, etc.) without testing any variables of personal contact (Jang et al., 2010). Most importantly, we largely replicated the associations between demographic variables and perceptions of the police, implying our results were solid. Thus, we believe our findings still added to the literature even without testing personal contact. However, we acknowledged that personal contact was an important factor relating to how people perceived the police. Adding this variable can further advance our knowledge about views on the police. Future studies can expand our results by including personal contact.

Similar to personal contact, past research revealed the effects of media on perceptions of the police. For example, Weitzer and Tuch (2006) found negative media report was associated with negative views on the police. By contrast, watching crime-based reality programs (e.g., crime case investigation) increased residents' trust and confidence in the police (Callanan \& Rosenberg, 2011). How the interaction between the public and media affects views on the police is complex because a variety of variables, including susceptibility to media, media type, news content, news outlet ideology, the way in which information is framed, may all be involved in the process of attitude formation. Studies on perceptions of the police in the past did not always include media-related variables as essential factors (e.g., Cao \& Stack, 2005; Jesilow et al., 1995; Schuck et al., 2008). Thus, a series of studies are in demand to elucidate the role of media and cognitive factors in perceptions of the police. However, as discussed, as the current study largely replicated past findings, we do not believe lacking media-related variables would fundamentally change our results.

External validity. The present study collected data from U.S. residents and one might be concerned about its external validity. Such a concern is reasonable and should be addressed with further studies. Our thoughts on this issue have two aspects. On one hand, we believe our results still have the potential to be generalized for two reasons. First, the psychological factors of need for cognition and numeracy are two essential traits. These two traits have been tested in different countries and shown similar functions. For example, with regards to intertemporal choice, higher numerate participants in some European countries and United States exhibited a stronger preference toward the later larger gains over the sooner smaller gains (Ghazal, Cokely, \& Garcia-Retamero, 2014; Cheng, 2020). Additionally, a positive relationship was found between need for cognition and academic performance in students in the United States, Turkey and The Netherlands (Akpur, 2017; Elias \& Loomis, 2002; Heijne-Penninga, Kuks, Hofman, \& Cohen-Schotanus, 2010). Therefore, the role of need for cognition and numeracy found in the present study has the potential to be discovered in a different nation.

Second, several past studies indicated similarities and commonalities in perceptions of the police between countries. For example, a comparison between the United States and Australia found that age, negative personal contact with police, and local safety problems all played a significant role in perceptions of the police (Dai \& Jiang, 2016). In a study comparing the views on the police between Japan and United States, age, political ideology, marriage status and life satisfaction were significant predictors (Cao \& Stack, 2005). Additionally, a study with data from fifteen countries on five continents found that after controlling for crime rates and level of democ- 
racy between different countries, age, political ideology and life satisfaction could significantly predict attitudes toward the police (Jang et al., 2010). Similarly, after surveying twenty-six European countries, Canada and United States, it was found the predictors of age, being asked for a bribe, fear of crime and police size were significant in predicting the perceptions of the police (Ivković, 2008). Similar to these studies, we also found the significant role of age, political ideology and crime rate in the present study. Therefore, although the current work was based on the public in the United States, we believe our study provided some initial evidence about the role of cognition in the perceptions of the police.

On the other hand, it is also worth noting that our hypotheses were based on the fact that crime rate decreased gradually in the United States and people tended to have a positive view on the police in general. For countries with high crime rates or concerning safety situation, the effect of need for cognition and numeracy (and other psychological factors as well) may be different because the public in these countries is less likely to recognize the work of the police. Thus, we believe the findings from the present study are more likely to be generalized to countries with relatively good public safety than to countries with poor public safety. Taken together, external validity is an important issue as countries differ in culture, value, ideology, income and other factors. We strongly believe more studies are needed to extend our findings to different countries.

Magnitude of the relationships. In addition to statistical significance, the magnitude of the relationship should also be taken into account. Based on zero-order correlations, the relationships between perceptions of the police and both objective and subjective numeracy were approaching a medium level. The relationship between need for cognition and perceptions of the police was relatively weak, despite its statistical significance. In regression, after controlling for demographics and crime rate, need for cognition and subjective numeracy were significantly related to perceptions of the police. The significance of objective numeracy was also close to the threshold (objective numeracy was significant if it was tested separately from subjective numeracy as shown in the appendix). However, the magnitudes of these relationships (as indicated by beta coefficients in the second block) were not as strong as those with age, race and ideology, and were close to those with party affiliation. Thus, on the one hand, the present study revealed a unique function of psychological factors in how people perceived the police. On the other hand, the findings also suggested that perceptions of the police were associated with a variety of factors and the role of demographics should not be underestimated.

Crime rate estimate. The present study did not ask participants for their location or perceived safety. Instead, the study used IP address to track zip code and found corresponding crime rate. Admittedly, this approach was relatively novel and indirect, and might result in inaccurate results. For instance, a person might complete our survey in a location that was far away from her/his living place. Although consistent with other studies, we found a negative relationship between our estimated crime rate and perceptions of the police; this approach's validity demands more studies with multiple measures to examine. However, the present study's main topic was about the role of psychological factors in perceptions of the police. We believe the results discovered in the present study were not affected by the validity of crime rate because the results changed little between including and excluding the crime rate variable (see Table 4 and Table $A 1$ in the appendix). 
In sum, the present study replicated the role of demographics in perceptions of the police. The study also found that how people perceived the police was also associated with their cognitive style and ability.

\section{Authors' ORCID \\ Carolyn Pham \\ https://orcid.org/0000-0002-0989-1116 \\ Jiuqing Cheng \\ https://orcid.org/0000-0003-4195-4882}

\section{References}

Arafat-Payne, Y. A., Hitchens, B. K., \& Chambers, D. L. (2017). "Why I can't stand out in front of my house?": Street-identified black youth and young adult's negative encounters with police. Sociological Forum, 33(1), 281-292. https://doi. org/10.1111/socf.12380

Akpur, U. (2017). The predictive degree of university students' level of metacognition and need for cognition on their academic achievement. European Journal of Foreign Language Teaching, 2, 52-63. http://doi.org/10.5281/zenodo.569538

Almashat, S., Ayotte, B., Edelstein, B., \& Margrett, J. (2008). Framing effect debiasing in medical decision making. Patient Educational Counseling, 7(1), 102-107. https://doi.org/10.1016/i. pec.2007.11.004

American Psychological Association. (2015). A reproducibility crisis? Retrieved from https://www. apa.org/monitor/2015/10/share-reproducibility

Barboza, G. E. (2012). Group consciousness, identity and perceptions of unfair police treatment among Mexican Americans. Policing: An International Journal of Police Strategies \& Management, 35(3), 505-527. https://doi.org/10.1108/13639511211250776

Brandl, S. G., \& Horvath, F. (1991). Crime-victim evaluation of police investigative performance. Journal of Criminal Justice, 19(3), 293-305. https://doi.org/10.1016/0047-2352(91)90008-J

Brown, A. (2017, January 13). Wide partisan gap in views of police. Retrieved from https://www. pewresearch.org/fact-tank/2017/01/13/republicans-more-likely-than-democrats-to-have-confidence-in-police/
Brown, B., \& Benedict, W. R. (2002). Perceptions of the police: Past findings, methodological issues, conceptual issues and policy implications. Policing: An International Journal of Police Strategies \& Management, 25(3), 543-580. https://doi. org/10.1108/13639510210437032

Cacioppo, J. T., \& Petty, R. E. (1982). The need for cognition. Journal of Personality and Social Psychology, 42(1), 116-131. https://doi. org/10.1037/0022-3514.42.1.116

Cacioppo, J. T., Petty, R. E., \& Kao, C. F. (2013). Need for Cognition Scale. Measurement Instrument Database for Social Science. Retrieved from www.midss.ie

Cacioppo, J. T., Petty, R. E., Feinstein, J. A., \& Jarvis, W. B. G. (1996). Dispositional differences in cognitive motivation: The life and times of individuals varying in need for cognition. Psychological Bulletin, 119, 197-253. https:// doi.org/10.1037/0033-2909.119.2.197

Callanan, V. J., \& Rosenberger, J. S. (2011). Media and public perceptions of the police: Examining the impact of race and personal experience. Policing \& Society, 21, 167-189. https://doi.org/ 10.1080/10439463.2010.540655

Cao, L. (2011). Visible minorities and confidence in the police. Canadian Journal of Criminology and Criminal Justice, 53(1), 1-26. https://doi. org/10.3138/cjccj.53.1.1

Cao, L., \& Stack, S. (2005). Confidence in the police between America and Japan: Results from two waves of surveys. Policing: An International Journal, 28, 139-151. https://doi. org/10.1108/13639510510581020

Cao, L., \& Wu. Y. (2019) Confidence in the police by race: Taking stock and charting new directions. Police Practice and Research, 20(1), 3-17. https://doi.org/10.1080/15614263.2017.13964 $\underline{60}$

Cao, L., Zhao, J., Ren, L., \& Zhao, R. (2015). Do ingroup and out-group forms of trust matter in predicting confidence in the order institutions? A study of three culturally distinct countries. International Sociology, 30(6), 674-693. https:// doi.org/10.1177/0268580915605651

Chalfin, A., \& McCrary, J. (2013). The effect of police on crime: New evidence from US cities, 1960-2010 (No. w18815). National Bureau of Economic Research. 
Chalfin, A., \& McCrary, J. (2018). Are U.S. cities underpoliced? Theory and evidence. Review of Economics and Statistics, 100(1), 167-186. https://doi.org/10.1162/REST a 00694

Cheng, J. (2020). The role of numeracy and impulsivity in intertemporal choice and decision making. Psychological Thought, 13(1), 254-272. https://doi.org/10.37708/psyct.v13i1.442

Choe, J. (2008). Income inequality and crime in the United States. Economics Letters, 101, 31-33. https://doi.org/10.1016/i.econlet.2008.03.025

Cohen, J. (1988). Statistical power analysis for the behavioral sciences (2nd ed.). Hillsdale, NJ: Lawrence Earlbaum Associates. https://doi. org/10.4324/9780203771587

Dai, M., \& Jiang, X. (2016). A comparative study of satisfaction with the police in the United States and Australia. Australian \& New Zealand Journal of Criminology, 49, 30-52. https://doi. org/10.1177/0004865814545684

Drakulish, K. M., \& Crutchfield, R. D. (2013). The role of perceptions of the police in informal social control: Implications for the racial stratification of crime and control. Social Problems, 60, 383407. https://doi.org/10.1525/sp.2013.60.3.383

Ekins, E. E. (2016). Policing in America: Understanding public attitudes toward the police. Results from https://www.cato.org/survey-reports/policing-america

Elias, S. M. \& Loomis, R. J. (2002), Utilizing need for cognition and perceived self-efficacy to predict academic performance1. Journal of Applied Social Psychology, 32, 1687-1702. https://doi. org/10.1111/i.1559-1816.2002.tb02770.x

Fagerlin, A., Zikmund-Fisher, B. J., Ubel, P. A., Jankovic, A., Derry, H. A., \& Smith, D. M. (2007). Measuring numeracy without a math test: Development of the Subjective Numeracy Scale (SNS). Medical Decision Making, 27(5), 672-680. https://doi.org/10.1177/0272989X07304449

Fingerhut, H. (2017). Republicans skeptical of colleges' impact on US, but most see benefits for workforce preparation. Pew Research Center. Retrieved from https://www.pewresearch.org/ fact-tank/2017/07/20/republicans-skeptical-ofcolleges-impact-on-u-s-but-most-see-benefitsfor-workforce-preparation/

Frank, J., Smith, B. W., \& Novak, K. J. (2005). Exploring the basis of citizens' attitudes toward the police. Police Quarterly, 8(2), 206-228. https:// doi.org/10.1177/1098611103258955

Frederick, S. (2005) Cognitive reflection and decision making. Journal of Economic Perspectives, 19(4), 2542. https://doi.org/10.1257/089533005775196732

Garcia, V., \& Cao, L. (2005). Race and satisfaction with the police in a small city. Journal of Criminal Justice, 33(2), 191-199. https://doi. org/10.1016/i.jcrimjus.2004.12.010

Ghazal, S., Cokely, E., \& Garcia-Retamero, R. (2014). Predicting biases in very highly educated samples: Numeracy and metacognition. Judgment and Decision Making, 9, 15-34.

Gramlich, J. (2019). 5 facts about crime in the U.S. Pew Research Center. Retrieved from https:// www.pewresearch.org/fact-tank/2019/10/17/ facts-about-crime-in-the-u-s/

Heijne-Penninga, M., Kuks, J. B. M., Hofman, W. H. A., \& Cohen-Schotanus, J. (2010). Influences of deep learning, need for cognition and preparation time for an open- and closed-book test performance. Medical Education, 44, 884-891. https://doi.org/10.1111/ j.1365-2923.2010.03732.x

Ivković, S. (2008). A comparative study of public support for the police. International Criminal Justice Review. 18, 406-434. https://doi. org/10.1177/1057567708326481

Jang, H., Joo, H. J., \& Zhao, J. S. (2010). Determinants of public confidence in the police: An international perspective. Journal of Criminal Justice, 38(1), 57-68. https://doi.org/10.1016/i. jcrimjus.2009.11.008

Jasper, J. D., Bhattacharya, C., \& Corser, R. (2017). Numeracy predicts more effortful and elaborative search strategies in a complex risky choice context: A process-tracing approach. Journal of Behavioral Decision, 30(2), 224-235. https://doi. org/10.1002/bdm.1934

Jesilow, P., Meyer, J., \& Namazzi, N. (1995). Public attitudes toward the police. American Journal of Police, 14(2), 67-88. https://doi. org/10.1108/07358549510102767

Juric, M. (2017). The role of need for cognition in the university students' reading behaviour. Information Research, 22(1), 1-16.

Kahneman, D. (2003). A perspective on judgment and choice: Mapping bounded rationality. American Psychologist, 58(9), 697-720. https://doi. org/10.1037/0003-066X.58.9.697 
Lai, Y. L., \& Zhao, J. S. (2010). The impact of race/ ethnicity, neighborhood context, and police/ citizen interaction on residents' attitudes toward the police. Journal of Criminal Justice, 38(4), 685-692. https://doi.org/10.1016/i.jcrimjus.2010.04.042

Levay, K. E., Freese, J., \& Druckman, J. N. (2016). The demographic and political composition of Mechanical Turk samples. SAGE Open, 6(1). https://doi.org/10.1177/2158244016636433

Liberali, J. M., Reyna, V. F., Furlan, S., Stein, L. M., \& Pardo, S. T. (2012). Individual differences in numeracy and cognitive reflection, with implications for biases and fallacies in probability judgment. Journal of Behavioral Decision Making, 25(4), 361-381. https://doi.org/10.1002/ $\underline{\text { bdm.752 }}$

Manning, P. K. (2010). Democratic policing in a changing world. Boulder: Paradigm Publishers. https://doi.org/ 10.1080/10439463.2011.641554

Maxwell, S. E., Kelley, K., \& Rausch, J. R. (2008). Sample size planning for statistical power and accuracy in parameter estimation. Annual Review of Psychology, 59, 537-563. https://doi. org/10.1146/annurev.psych.59.103006.093735

McCluskey, J., McCluskey, C., \& Enriquez, R. (2008). A comparison of Latino and White citizen satisfaction with police. Journal of Criminal Justice, 36, 471-477. https://doi.org/10.1016/i.jcrimjus.2008.09.012

MacDonald, J., \& Stokes, R. (2006). Race, social capital, and trust in the police. Urban Affairs Review, 41,358375. https://doi.org/10.1177/1078087405281707

Motley, R., \& Joe, S. (2018). Police use of force by ethnicity, sex, and socioeconomic class. Journal of the Society for Social Work and Research, 9(1), 49-67. https://doi.org/10.1086/703356

Myhill, A., \& Bradford, B. (2012). Can police enhance public confidence by improving quality of service? Results from two surveys in England and Wales. Policing and Society, 22(4), 397-425. https://doi.org/10.1080/10439463.2011.64155 $\underline{1}$

Nadal, K. L., \& Davidoff, K. C. (2015). Perceptions of police scale (POPS): Measuring attitudes towards law enforcement and beliefs about police bias. Journal of Psychology and Behavioral Science, 3(2), 1-9. http://dx.doi.org/10.15640/ jpbs.v3n2a1
Patel, N. (2017). The cognitive reflection test: $A$ measure of intuition/reflection, numeracy, and insight problem solving, and the implications for understanding real-world judgements and beliefs (Unpublished master's thesis). University of Missouri-Columbia, Columbia, Missouri.

Peck, J. H. (2015). Minority perceptions of the police: A state-of-the-art review. Policing: An International Journal, 38(1), 173-203. https://doi. org/10.1108/PIJPSM-01-2015-0001

Pennycook, G., \& Rand, D. G. (2019). Cognitive Reflection and the 2016 U.S. Presidential Election. Personality and Social Psychology Bulletin, 45(2), 224-239. https://doi.org/10.1177/0146167218783192

Peters, E., \& Bjalkebring, P. (2015). Multiple numeric competencies: When a number is not just a number. Journal of Personality and Social Psychology, 108(5), 802-822. https://doi. org/10.1037/pspp0000019

Petty, R. E., Briñol, P., Loersch, C., \& McCaslin, M. J. (2009). The need for cognition. In M. R. Leary \& R. H. Hoyle (Eds.), Handbook of individual differences in social behavior (pp. 318-329). New York: Guilford.

Pew Research Center (2017, September 13). Partisans differ widely in views of police officers, college professors. Retrieved from https://www. people-press.org/2017/09/13/partisans-differ-widely-in-views-of-police-officers-college-professors/

Reisig, M., \& Parks, R. (2000). Experience, quality of life, and neighborhood context. Justice Quarterly, 17(3), 607-629. https://doi. org/10.1080/07418820000094681

Ren, L., Cao, L., Lovrich, N., \& Gaffney, M. (2005). Linking confidence in the police with the performance of the police. Journal of Criminal Justice, 33(1), 55-66. https://doi.org/10.1016/i.jcrimjus.2004.10.003

Reyna, V. F., Nelson, W. L., Han, P. K., \& Dieckmann, N. F. (2009). How numeracy influences risk comprehension and medical decision making. Psychological Bulletin, 135(6), 943. https://doi. org/10.1037/a0017327

Sampson, R. J., \& Bartusch, D. J. (1998). Legal cynicism and (subcultural?) tolerance of deviance: The neighborhood context of racial differences. Law and Society Review 32, 777-804. https:// doi.org/10.2307/827739 
Schuck, A. M., Rosenbaum, D. P., \& Hawkins, D. F. (2008) The influence of race/ethnicity, social class, and neighborhood context on residents' attitudes toward the police. Police Quarterly, 11(4), 496-519. https:// doi.org/10.1177/1098611108318115

Sinayev, A., \& Peters, E. (2015). Cognitive reflection vs. calculation in decision making. Frontiers in Psychology, 6, 532. https://doi.org/10.3389/ fpsyg.2015.00532

Slovic, P., Fischhoff, B., \& Lichtenstein, S., \& Roe, F. (1981). Perceived risk: Psychological factors and social implications. Proceedings of The Royal Society A: Mathematical, Physical and Engineering Sciences, 376, 17-34. https://doi.org/10.1098/ rspa.1981.0073

Stack, S., Cao, L., \& Adamzyck, A. (2007). Crime volume and law and order culture. Justice Quarterly, 24(2), 291308. https://doi.org/10.1080/07418820701294839

Sumner, C., Scofield, J. E., Buchanan, E. M., Evans, M., \& Shearing, M. (2018, July 3). The role of personality, authoritarianism and cognition in the United Kingdom's 2016 referendum on European Union membership. https://doi.org/10.31219/ osf.io/n5r67

Sunshine, J., \& Tyler, T. R. (2003). The role of procedural justice and legitimacy in shaping public support for policing. Law and Society Review, 37(3), 513-548. https://doi.org/10.1111/1540$\underline{5893.3703002}$

Taylor, R. B., \& Lawton, B. A. (2012). An integrated contextual model of confidence in local police. Police Quarterly, 15(4), 414-445. https://doi. org/10.1177/1098611112453718

Thomson, K. S., \& Oppenheimer, D. M. (2016). Investigating an alternate form of the cognitive reflection test. Judgement and Decision Making, 11(1), 99-113.

Tversky, A., \& Kahneman, D. (1974). Judgement under uncertainty: Heuristics and biases. Science, 185, 1124-1131. https://doi.org/10.1126/science.185.4157.1124

Tversky, A., \& Kahneman, D. (1981). The framing of decisions and the psychology of choice. Science, 211(4481), 453-458. https://doi.org/10.1126/ science. 7455683
Tversky, A., \& Kahneman, D. (2002). Extensiona versus intuitive reasoning: The conjunction fallacy in probability judgment. Heuristics and biases: The psychology of intuitive judgment (pp. 19-48). Cambridge University Press, New York, NY, US.

Verplanken, B., Hazenberg, P. T., \& Palenéwen, G. R. (1992). Need for cognition and external information search effort. Journal of Research in Personality, 26(2), 128-136. https://doi. org/10.1016/0092-6566(92)90049-A

Weller, J. A., Dieckmann, N. F., Tusler, M., Mertz, C. K., Burns, W. J., \& Peters, E. (2013). Development and testing of an abbreviated numeracy scale: A Rasch analysis approach. Journal of Behavioral Decision Making, 26(2), 198-212. https://doi. org/10.1002/bdm.1751

Weitzer, R., \& Tuch, S. (2002). Perceptions of racial profiling: Race, class, and personal experience. Criminology, 40, 435-456. https://doi. org/10.1111/i.1745-9125.2002.tb00962.x

Weitzer, R., \& Tuch, S. A. (2005). Racially biased policing: Determinants of citizen perceptions. Social Forces, 83(3), 1009-1030. https://doi. org $/ 10.1353 /$ sof.2005.0050

Weitzer, R., \& Tuch, S. A. (2006). Race and policing in America: Conflict and reform. Cambridge, UK: Cambridge University Press. https://doi. org/10.1017/CBO9780511617256

West, R. F., Toplak, M. E., \& Stanovich, K. E. (2008). Heuristics and biases as measures of critical thinking: Associations with cognitive ability and thinking dispositions. Journal of Educational Psychology, 100(4), 930-941. https://doi. org/10.1037/a0012842

Wu, Y. (2014). Race/ethnicity and perceptions of the police: A comparison of White, Black, Asian, and Hispanic Americans. Policing and Society, 24(2), 135-157. https://doi.org/10.1080/10439 $\underline{463.2013 .784288}$

Wu, Y., Lake, R., \& Cao, L. (2015). Race and social bonds on juvenile trust in the police. Justice Quarterly, 32(3), 445-470. https://doi.org/10.1 $\underline{080 / 07418825.2013 .778325}$ 


\section{Appendix}

Table A1 displays the hierarchical linear regression without the variable of crime rate. Adding the variable of crime rate or not did not change our conclusion regarding the role of need for cognition and numeracy in perceptions of the police.

Table A1 Regression: effects of need for cognition and subjective and objective numeracy in the presence of the demographic variables

\begin{tabular}{|c|c|c|c|c|c|c|}
\hline Blocks and Variables & $\mathrm{B}(\mathrm{SE})$ & Beta & $R^{2}$ & $\begin{array}{c}R^{2} \\
\text { change }\end{array}$ & $\begin{array}{c}F \\
\text { change }\end{array}$ & Tolerance \\
\hline Block 1 & & & .21 & .21 & $10.67^{* * *}$ & \\
\hline Age & $.01(.003)^{* * *}$ & $.19^{* * *}$ & & & & .78 \\
\hline Gender & $-.11(.09)$ & -.06 & & & & .95 \\
\hline Whites vs. Blacks & $.37(.12)^{* *}$ & $.18^{* *}$ & & & & .54 \\
\hline Hispanics vs. Blacks & $.38(.13)^{* *}$ & $.16^{* *}$ & & & & .67 \\
\hline Asians vs. Blacks & $.50(.12)^{* *}$ & $.23^{* *}$ & & & & .59 \\
\hline Education & $.07(.04)$ & .08 & & & & .73 \\
\hline Income & $.02(.01)$ & .09 & & & & .77 \\
\hline Ideology & $.09(.03)^{* *}$ & $.16^{* *}$ & & & & .79 \\
\hline Democrats vs. Republicans & $-.30(.13)^{*}$ & $-.16^{*}$ & & & & .41 \\
\hline Independents vs. Republicans & $-.31(.13)^{* *}$ & $-.16^{* *}$ & & & & 50 \\
\hline Block 2 & & & .27 & .06 & $9.43^{* * *}$ & \\
\hline Age & $.01(.003)^{* * *}$ & $.19^{* * *}$ & & & & .77 \\
\hline Gender & $-.16(.09)$ & -.09 & & & & .92 \\
\hline Whites vs. Blacks & $.34(.12)^{* *}$ & $.17^{* *}$ & & & & .53 \\
\hline Hispanics vs. Blacks & $.39(.13)^{* *}$ & $.16^{* *}$ & & & & .67 \\
\hline Asians vs. Blacks & $.41(.13)^{* *}$ & $.20^{* *}$ & & & & .53 \\
\hline Education & $.03(.04)$ & .03 & & & & .70 \\
\hline Income & $.02(.01)$ & .07 & & & & .77 \\
\hline Ideology & $.09(.03)^{* *}$ & $.17^{* *}$ & & & & .78 \\
\hline Democrats vs. Republicans & $-.27(.13)^{*}$ & $-.15^{*}$ & & & & .40 \\
\hline Independents vs. Republicans & $-.25(.12)^{*}$ & $-.13^{*}$ & & & & .49 \\
\hline Need for Cognition & $.15(.07)^{*}$ & $.10^{*}$ & & & & .91 \\
\hline Subjective Numeracy & $.12(.04)^{* *}$ & $.15^{* *}$ & & & & .72 \\
\hline Objective Numeracy & $.04(.02)^{\mathrm{a}}$ & $.09^{\mathrm{a}}$ & & & & .71 \\
\hline
\end{tabular}

Note. Gender: female was the reference level, Race: Blacks is the reference level, Ideology: a larger value indicates more conservative.

${ }^{*} p<.05 ;{ }^{* *} p<.01 ;{ }^{* * *} p<.001 ;$ a: $p<.10$ 
Tables A2 and A3 respectively show the hierarchical linear regression when testing subjective numeracy and objective numeracy separately. As shown, both numeracy variables were significant in the corresponding analyses.

Table A2 Regression: effects of need for cognition and subjective numeracy in the presence of the demographic variables and crime rate

\begin{tabular}{|c|c|c|c|c|c|c|}
\hline Blocks and Variables & $\mathrm{B}(\mathrm{SE})$ & Beta & $R^{2}$ & $\begin{array}{c}R^{2} \\
\text { change }\end{array}$ & $\begin{array}{c}F \\
\text { change }\end{array}$ & Tolerance \\
\hline Block 1 & & & .22 & .22 & $9.61^{* * *}$ & \\
\hline Age & $.01(.003)^{* * *}$ & $.20^{* * *}$ & & & & .78 \\
\hline Gender & $-.09(.09)$ & -.05 & & & & .95 \\
\hline Whites vs. Blacks & $.34(.12)^{* *}$ & $.17^{* *}$ & & & & .53 \\
\hline Hispanics vs. Blacks & $.38(.13)^{* *}$ & $.16^{* *}$ & & & & .67 \\
\hline Asians vs. Blacks & $.50(.11)^{* *}$ & $.24^{* *}$ & & & & .58 \\
\hline Education & $.07(.05)$ & .08 & & & & .73 \\
\hline Income & $.02(.01)$ & .08 & & & & .75 \\
\hline Ideology & $.09(.03)^{* *}$ & $.16^{* *}$ & & & & .79 \\
\hline Democrats vs. Republicans & $-.27(.13)^{*}$ & $-.15^{*}$ & & & & .40 \\
\hline Independents vs. Republicans & $-.30(.13)^{*}$ & $-.15^{*}$ & & & & .50 \\
\hline Crime rate & $\begin{array}{l}-2.9 * 10^{-5} \\
\left(2.6 * 10^{-5}\right)\end{array}$ & -.05 & & & & .91 \\
\hline Block 2 & & & .27 & .05 & $13.23^{* * *}$ & \\
\hline Age & $.01(.003)^{* * *}$ & $.21^{* * *}$ & & & & .78 \\
\hline Gender & $-.13(.09)$ & -.07 & & & & .93 \\
\hline Whites vs. Blacks & $.34(.12)^{* *}$ & $.17^{* *}$ & & & & .53 \\
\hline Hispanics vs. Blacks & $.39(.13)^{* *}$ & $.17^{* *}$ & & & & .67 \\
\hline Asians vs. Blacks & $.49(.12)^{* *}$ & $.23^{* *}$ & & & & .57 \\
\hline Education & $.03(.05)$ & .03 & & & & .70 \\
\hline Income & $.02(.01)$ & .06 & & & & .75 \\
\hline Ideology & $.09(.03)^{* *}$ & $.16^{* *}$ & & & & .78 \\
\hline Democrats vs. Republicans & $-.24(.13)$ & $-.13^{a}$ & & & & .40 \\
\hline Independents vs. Republicans & $-.25(.13)$ & $-.13^{*}$ & & & & .49 \\
\hline Crime rate & $\begin{array}{l}-4.2 * 10^{-5} \\
\left(2.6 * 10^{-5}\right)\end{array}$ & -.08 & & & & .90 \\
\hline Need for Cognition & $.17(.07)^{*}$ & $.11^{*}$ & & & & .92 \\
\hline Subjective Numeracy & $.16(.04)^{* *}$ & $.19^{* *}$ & & & & .82 \\
\hline
\end{tabular}

Note. Gender: female was the reference level, Race: Blacks is the reference level, Ideology: a larger value indicates more conservative.

${ }^{*} p<.05 ;{ }^{* *} p<.01 ;{ }^{* * *} p<.001 ; \mathrm{a}: p<.10$ 
Table A3 Regression: effects of need for cognition and objective numeracy in the presence of the demographic variables and crime rate

\begin{tabular}{|c|c|c|c|c|c|c|}
\hline Blocks and Variables & $\mathrm{B}(\mathrm{SE})$ & Beta & $R^{2}$ & $\begin{array}{c}R^{2} \\
\text { change }\end{array}$ & $\begin{array}{c}F \\
\text { change }\end{array}$ & Tolerance \\
\hline Block 1 & & & .22 & .22 & $9.61^{* * *}$ & \\
\hline Age & $.01(.003)^{* * *}$ & $.20^{* * *}$ & & & & .78 \\
\hline Gender & $-.09(.09)$ & -.05 & & & & .95 \\
\hline Whites vs. Blacks & $.34(.12)^{* *}$ & $.17^{* *}$ & & & & .53 \\
\hline Hispanics vs. Blacks & $.38(.13)^{* *}$ & $.16^{* *}$ & & & & .67 \\
\hline Asians vs. Blacks & $.50(.11)^{* *}$ & $.24^{* *}$ & & & & .58 \\
\hline Education & $.07(.05)$ & .08 & & & & .73 \\
\hline Income & $.02(.01)$ & .08 & & & & .75 \\
\hline Ideology & $.09(.03)^{* *}$ & $.16^{* *}$ & & & & .79 \\
\hline Democrats vs. Republicans & $-.27(.13)^{*}$ & $-.15^{*}$ & & & & .40 \\
\hline Independents vs. Republicans & $-.30(.13)^{*}$ & $-.15^{*}$ & & & & .50 \\
\hline Crime rate & $\begin{array}{c}-2.9 * 10^{-5} \\
\left(2.6 * 10^{-5}\right)\end{array}$ & -.05 & & & & .91 \\
\hline Block 2 & & & .26 & .04 & $10.30^{* * *}$ & \\
\hline Age & $.01(.003)^{* * *}$ & $.19^{* * *}$ & & & & .78 \\
\hline Gender & $-.12(.08)$ & -.06 & & & & .93 \\
\hline Whites vs. Blacks & $.33(.13)^{* *}$ & $.16^{* *}$ & & & & .53 \\
\hline Hispanics vs. Blacks & $.38(.13)^{* *}$ & $.16^{* *}$ & & & & .67 \\
\hline Asians vs. Blacks & $.41(.13)^{* *}$ & $.19^{* *}$ & & & & .57 \\
\hline Education & $.05(.05)$ & .06 & & & & .70 \\
\hline Income & $.02(.01)$ & .07 & & & & .75 \\
\hline Ideology & $.10(.03)^{* * *}$ & $.18^{* * *}$ & & & & .78 \\
\hline Democrats vs. Republicans & $-.22(.13)$ & -.12 & & & & .40 \\
\hline Independents vs. Republicans & $-.24(.13)$ & $-.12^{\mathrm{a}}$ & & & & .49 \\
\hline Crime rate & $\begin{array}{l}-2.8 * 10^{-5} \\
\left(2.6 * 10^{-5}\right)\end{array}$ & -.06 & & & & .90 \\
\hline Need for Cognition & $.21(.07)^{* *}$ & $.14^{* *}$ & & & & .92 \\
\hline Objective Numeracy & $.07(.02)^{* *}$ & $.15^{* *}$ & & & & .82 \\
\hline
\end{tabular}

Note. Gender: female was the reference level, Race: Blacks is the reference level, Ideology: a larger value indicates more conservative.

${ }^{*} p<.05 ;{ }^{* *} p<.01 ;{ }^{* * *} p<.001 ; \mathrm{a}: p<.10$ 